\title{
Neuromotor Effects of Acute Ethanol Inhalation Exposure in Humans: A Preliminary Study
}

\author{
Véronique Nadeau ${ }^{1}$, Daniel Lamoureux ${ }^{2}$, Anne Beuter ${ }^{2,3}$, Michel Charbonneau ${ }^{4}$ and \\ Robert TARDIF ${ }^{1}$
}

${ }^{1}$ TOXHUM (Groupe de Recherche en Toxicologie Humaine), Département de Santé Environnementale et Santé au Travail, Université de Montréal, ${ }^{2}$ Centre de Neuroscience de la Cognition, Université du Québec à Montréal, Canada, ${ }^{3}$ Institut de Biologie, Laboratoire de Physiologie, Université de Montpellier 1, France and ${ }^{4}$ INRS-Santé/ Institut Armand Frappier, Pointe-Claire, Canada

\begin{abstract}
Neuromotor Effects of Acute Ethanol Inhalation Exposure in Humans: A Preliminary Study: Véronique NADEAU, et al. TOXHUM (Groupe de Recherche en Toxicologie Humaine), Département de Santé Environnementale et Santé au Travail, Université de Montréal, CanadaEthanol (ETOH) is added to unleaded gasoline to decrease environmental levels of carbon monoxide from automobiles emissions. Therefore, addition of ETOH in reformulated fuel will most likely increase and the involuntarily human exposure to this chemical will also increase. This preliminary study was undertaken to evaluate the possible neuromotor effects resulting from acute ETOH exposure by inhalation in humans. Five healthy non-smoking adult males, with no history of alcohol abuse, were exposed by inhalation, in a dynamic, controlled-environment exposure chamber, to various concentrations of $\operatorname{ETOH}(0,250,500$ and $1,000 \mathrm{ppm}$ in air) for six hours. Reaction time, body sway, hand tremor and rapid alternating movements were measured before and after each exposure session by using the CATSYS ${ }^{\mathrm{TM}} 7.0$ system and a diadochokinesimeter. The concentrations of $\mathrm{ETOH}$ in blood and in alveolar air were also measured. ETOH was not detected in blood nor in alveolar air when volunteers were exposed to 250 and 500 ppm, but at the end of exposure to $1,000 \mathrm{ppm}$, blood and alveolar air concentrations were $0.443 \mathrm{mg} / 100 \mathrm{~m} /$ and 253.1 ppm, respectively. The neuromotor tests did not show conclusively significant differences between the exposed and non-exposed conditions. In conclusion, this study suggests that acute exposure to ethanol at $1,000 \mathrm{ppm}$ or lower or to concentrations that could be
\end{abstract}

Received Oct 15, 2002; Accepted May 19, 2003

Correspondence to: R. Tardif, Université de Montréal, Département de Santé Environnementale et Santé au Travail C.P. 6128 Succursale Centre-Ville, H3C 5J7, Canada encountered upon refueling is not likely to cause any significant neuromotor alterations in healthy males. (J Occup Health 2003; 45:215-222)

Key words: Ethanol, Human, Vapors, Blood, Expired air, Neuromotor functions, Reaction time, Tremor

Ethanol (ETOH, ethyl alcohol, ethyl hydrate, $\left.\mathrm{C}_{2} \mathrm{H}_{6} \mathrm{OH}\right)$ is used as a fuel additive in the range of 5 to $10 \%$ in cars using unleaded gasoline. In specially designed cars, the fuel concentration of ethanol (ETOH) may reach $85 \%$ $(\mathrm{v} / \mathrm{v})$. It is used as an oxygenant to decrease automobile emissions of carbon monoxide ${ }^{1)}$. Considering the efforts to diminish toxic emissions in the environment, ETOH is likely to become a major fuel constituent. Therefore, involuntary exposures to ETOH may rise if ETOH content in fuel increases and it is clear that this new use of ETOH introduces inhalation as a new exposure route for humans. Under common ETOH utilisation conditions, users are also exposed to its vapours and this makes the respiratory system the major exposure route of $\mathrm{ETOH}$, so that it becomes necessary to evaluate the potential effects associated with such ETOH utilization.

The occupational standard limit for ethanol exposure in air is $1,000 \mathrm{ppm}(8 \mathrm{~h} / \mathrm{d}, 5 \mathrm{~d} / \mathrm{wk})$ for the Occupational Safety and Health Administration (OSHA), the American Conference of Government Industrial Hygienists (ACGIH) and the National Institute of Occupational Safety and Hygiene (NIOSH), based on temporary irritation of the eyes and the respiratory tract at this level of exposure or higher. At higher concentrations, ethanol vapours also induce headaches, fatigue, and sleepiness and affect the central nervous system (CNS). Since ETOH's toxic effects require its penetration into the bloodstream, airborne exposure can be evaluated by measuring blood ETOH concentrations (BAC) or breath 
alcohol ${ }^{2)}$. Endogenous levels of ETOH in blood usually range from 0.02 to $0.15 \mathrm{mg} \%$ in normal subjects ${ }^{3)}$ and the rate of clearance in humans is about $83 \mathrm{mg} / \mathrm{kg} / \mathrm{h}$ but may reach $127 \mathrm{mg} / \mathrm{kg} / \mathrm{h}$ in some individual ${ }^{4}$.

It is common knowledge that ingestion of ETOH affects the CNS and more particularly the frontal lobes, the occipital lobes and the cerebellum ${ }^{5,6}$. Recent studies have demonstrated that brain aldehyde dehydrogenase may contribute to the effects of ETOH on motor activity ${ }^{7}$ and that exhaled acetaldehyde could be measured and used as an exposure indicator after inhalation exposure of humans to low levels of ETOH (25-1,000 ppm $)^{8)}$.

Maintenance of standing posture, manual coordination and tremor have long been associated with the assessment of nervous system functions ${ }^{9-11)}$. The use of a quantitative sensorimotor test battery is worthwhile because it reduces subjectivity observed with clinical scale tests. Therefore, results can be used to make interpretations of the performance based on well-established facts ${ }^{11,12}$. Beuter and colleagues ${ }^{9)}$ reported that exposure to such substances as manganese and mercury affects the ability of subjects to perform rapid alternating movements such as pronation-supination and flexion-extension. Therefore, diadochokinesia have been shown to provide quantitative information about nervous system status. Moreover, measurement of postural sway and postural tremor becomes at this point a tool for neuronal damage detection and the use of the Sway ${ }^{\mathrm{TM}} 7.0$ is an appropriate way to compare neurological deficits with the clinical tests used for the same purpose ${ }^{12,13)}$.

Neuromotor effects after ETOH ingestion have been extensively studied, but effects after inhalation exposure to ETOH are not well established. Jones ${ }^{3)}$ reported acute alterations in body sway and hand tremor at peak blood concentrations after ingestion of $0.68 \mathrm{~g} / \mathrm{kg}$ of ETOH in men and no significant impairment when BAC reached $50-70 \mathrm{mg} \%$ in the postpeak phase. Kubo and colleagues ${ }^{14)}$ and Savolainen and Riihimäki ${ }^{15)}$ also reported changes in body sway in men after ingestion of $2.0-3.5 \mathrm{ml} / \mathrm{kg}$ of whisky (40\% of alcohol) and 400-800 mg/kg of alcohol, respectively.

Since ETOH concentrations in the air tend to increase, it is likely that human involuntary exposure might also increase. Therefore, it becomes necessary to evaluate the possible neuromotor effects of such exposure. The aim of this preliminary study is to see if acute ETOH exposure at concentrations near or below the current admissible level is likely to affect some sensitive markers of neuromotor disturbance in human volunteers.

\section{Materials and Methods}

Subjects: Five healthy right-handed adult men (nonsmokers; age, 22-53 yr) were recruited for this study. The volunteers who gave their informed consent were all social drinkers and had no history of drug or alcohol abuse. A detailed questionnaire was also administrated investigating substance abuse, as well as medical, surgical and psychiatric antecedents to ensure that possible confounders were not introduced. During the entire study, volunteers were instructed to avoid ingestion of ETOH and coffee during the 24 and $12 \mathrm{~h}$ preceding the exposures, respectively. Subjects were exposed on five different days $(6 \mathrm{~h} / \mathrm{d} ; 9 \mathrm{~h} 00$ to $15 \mathrm{~h} 00)$ to $\mathrm{ETOH}(0,250,500$ and 1,000 ppm). All exposures were separated at least by a $24-\mathrm{h}$ period to prevent accumulation of ETOH in the body. Exposures were not run in sequential order $(0,500,1,000$ and $250 \mathrm{ppm})$. Subjects were continuously under observation during each exposure session and remained seated almost all of the time, although they were free to move in the chamber. This protocol was approved by the Ethics Committee of the Faculty of Medicine (University of Montréal).

Solvents: ETOH (95\%) was obtained from Les Alcools de Commerce Inc. and was used to generate ETOH concentrations in the inhalation chamber. ETOH $100 \%$ from Sabex Inc. was used to prepare ETOH standard curves (for alveolar air and blood analyses).

Exposure Chamber: Exposures to ETOH were carried out in a dynamic controlled-environment exposure chamber measuring $18.1 \mathrm{~m}^{3}$. Purified air, which was introduced from the ceiling at a rate of $5.34 \mathrm{~m}^{3} / \mathrm{min}$, was temperature $\left(22^{\circ} \mathrm{C}\right)$ and humidity-controlled $(45 \%)$. ETOH atmospheres were generated by the introduction of ETOH by means of an high-pressure liquid chromatography (HPLC) pump (Varian Canada) into a $1-1$, three-necked, round-bottomed flask and mixed with clean, compressed air and then swept by aspiration into the inlet duct of the chamber. The concentration of ETOH in the chamber was monitored by automatic sampling of $1 \mathrm{~m} l$ of chamber atmosphere at intervals of $10 \mathrm{~min}$ into a gas chromatograph (Varian Chrompack 3800) equipped with a flame-ionisation detector. The column (DB-Wax, $30 \mathrm{~m}, 0.53 \mathrm{~mm}$ I.D.) was heated at $75^{\circ} \mathrm{C}$ whereas the temperature of the injection port and detector was set at $180^{\circ} \mathrm{C}$ and $250^{\circ} \mathrm{C}$, respectively. ETOH standards were prepared by using 10L Tedlar ${ }^{\circledR}$ bags. In addition, continuous monitoring of ETOH was carried out with an infrared spectrophotometer (MIRAN 1-A).

Measurement of ETOH in Blood and Alveolar Air: The concentration of ETOH in blood, taken from the antecubital vein, during exposure (at 3 and $6 \mathrm{~h}$ ) was measured by a head-space gas chromatographic technique under the same chromatographic conditions as described above. Calibration standards containing ETOH (0.084$1.678 \mathrm{mg} \%$ ) were prepared by adding ETOH to human control blood. The alveolar air concentration of ETOH was measured at $0,3,4.5$ and $6 \mathrm{~h}$ by injecting $1 \mathrm{~m} l$ of 
Table 1. Definitions of the specific parameters examined for neuromotor assessment

\begin{tabular}{|c|c|}
\hline Parameters & Definitions \\
\hline & Postural tremor \\
\hline $\begin{array}{l}\text { Tremor Intensity (TI) } \\
\quad\left(\text { Unit: } \mathrm{m} / \mathrm{s}^{2}\right)\end{array}$ & Root mean square (RMS) of acceleration recorded in the $0.9-15 \mathrm{~Hz}$ band. \\
\hline $\begin{array}{l}\text { Centre Frequency (CF) } \\
\text { (Unit: Hz) }\end{array}$ & Median frequency of the acceleration recorded in the $0.9-15 \mathrm{~Hz}$ band. \\
\hline $\begin{array}{l}\text { Frequency Dispersion (FD) } \\
\text { (Unit: Hz) }\end{array}$ & $\begin{array}{l}\text { Degree of irregularity of tremor. Frequency band centered on the medium frequency, which } \\
\text { contains } 68 \% \text { of the power. }\end{array}$ \\
\hline Harmonic Index (HI) & $\begin{array}{l}\text { Compares tremor frequency pattern with that of a single harmonic oscillation, which has a } \\
\mathrm{HI}=1.00 \text {. (Modified by Edwards and Beuter,1999) }\end{array}$ \\
\hline \multirow[t]{2}{*}{ Tremor Index (TI) } & An overall summary incorporating the 4 previous measures. (See Edwards and Beuter, 1999) \\
\hline & Body sway \\
\hline Transversal Sway (TS) (mm) & Simple mean of the recorded $\mathrm{x}$-direction values of the force centre in a coordinate system. \\
\hline Sagittal Sway (SS) (mm) & Simple mean of the recorded y-direction values of the force centre in a coordinate system. \\
\hline Sway Area (SA) $\left(\mathrm{mm}^{2}\right)$ & $\begin{array}{l}\text { Area of the smallest polygon, which includes the total trajectory of the force center in the } \\
\text { horizontal plane. }\end{array}$ \\
\hline \multirow[t]{2}{*}{ Sway Velocity (SV) (mm/s) } & Average travel speed of the force centre in the horizontal sway plate plane. \\
\hline & Diadochokinesia \\
\hline Range (Unit: degrees) & Mean of total angular displacement per cycle. \\
\hline Velocity (Unit : Degrees/s) & Mean velocity for each cycle averaged for all cycles. \\
\hline Maximum slope & $\begin{array}{l}\text { Maximum slope of a regression line fitted to seven successive data points and averaged for } \\
\text { each ascending and descending part of all the cycles. }\end{array}$ \\
\hline Coherence & Reflects the similarity of the oscillations in the two hands. \\
\hline
\end{tabular}

alveolar air collected in $3-\mathrm{L}$ Tedlar ${ }^{\circledR}$ bags into the chromatograph.

Evaluation of Neuromotor Functions: Neuromotor activity was examined with a diadochokinesimeter (Doco Microsystèmes Inc. Montreal, Canada) and a standard test battery (CATSYS 7.0 System ${ }^{\circledR}$; Danish Product Development Co., Denmark). The tests were administered before and immediately after each exposure session. Volunteers had a few seconds to practise with the apparatus before the first trial of the day to become familiar with the testing procedures.

The CATSYS 7.0 System ${ }^{\circledR}$ is a portable system including a datalogger used to quantify different neuromotor functions such as tremor, reaction time and postural sway. Postural tremor was measured successively for each hand for $24 \mathrm{~s}$ and repeated two times. Subjects had to hold a light stylus (Tremor ${ }^{\circledR}$ Pen) horizontally, parallel to the abdomen at approximately $10 \mathrm{~cm}$ in front of the navel and with the elbow joint bent at a right angle and free of the body. During the recording, subjects looked at the tip of the stylus, breathed normally and relaxed. The stylus recorded hand vibrations, and information was displayed in realtime in a time axis plot on the computer screen. Five key measures were calculated: Tremor Intensity (I), Centre Frequency (F50), Frequency dispersion (FD), modified Harmonic Index $(\mathrm{HI})$ and tremor index $(\mathrm{TI})^{16)}$. A short definition of each characteristic is shown in Table 1.

Reaction time was measured with a hand switch activated by the thumb with a sound stimulus coming from the datalogger. The test was done with both hands for $70 \mathrm{~s}$ each time. Parameters calculated from this test were mean reaction time (RT) and standard deviation (SD).

The Sway Analysis Test System (SWAYTM 7.0) is a platform containing 3 orthogonal strain-gauge devices. The subjects had to stand on the platform, feet at $1 \mathrm{~cm}$ from one another, with their arms at the sides, the body slightly tilted forward with body support coming from the front part of their feet. Subjects had to look at a picture placed at 6 feet in front of them, or keep their eyes closed. For each test, postural sway was measured for $75 \mathrm{~s}$ (a $10 \mathrm{~s}$ start-up period, a $60 \mathrm{~s}$ recording period and a $5 \mathrm{~s}$ run-out period). Sway parameters calculated included: Transversal Sway (TS), Sagittal Sway (SS), Sway Area (SA) and Sway Velocity (SV). Table 1 gives a definition of these characteristics.

The Diadiochokinesimeter is a system used to quantify 
a

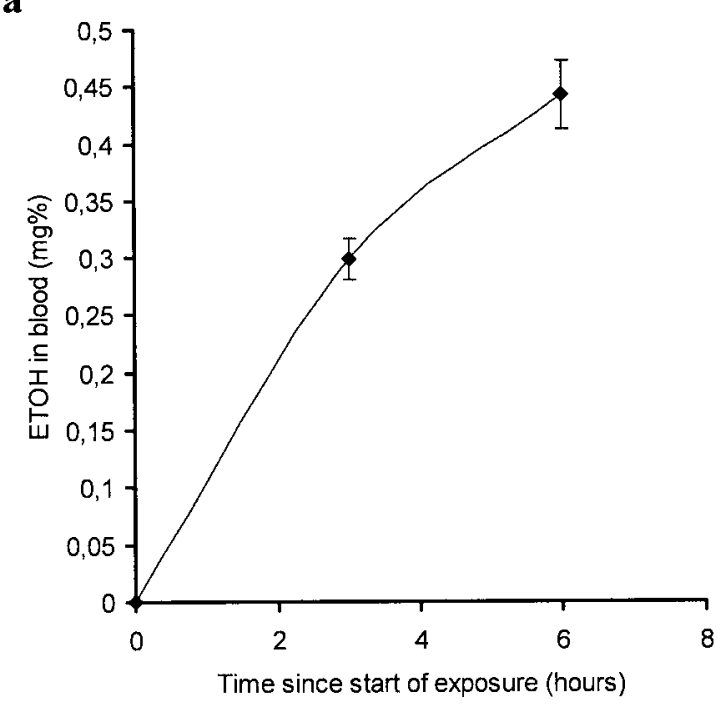

b

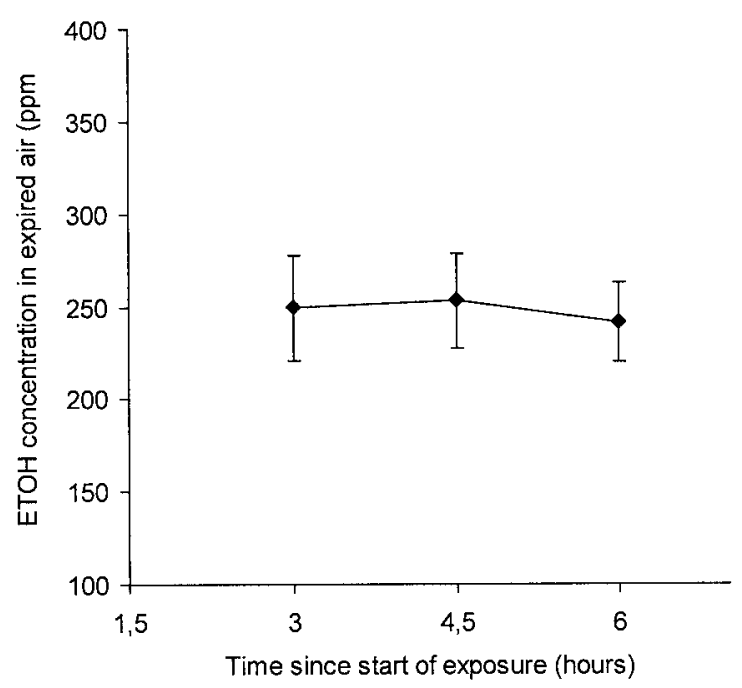

Fig. 1. ETOH concentrations in blood (a) and expired air (b) in five men after a 6-h inhalation exposure to 1,000 ppm of ETOH.

rapid alternating movements (RAMs) in a quick and simple way. This system records both hands, and the multidirectional joint connecting the rods to the system allows some subjects with movement disorders to still be able to complete the test. For a more complete description of the method, refer to Beuter and colleagues $^{16)}$. Subjects sat in front of the system and held the foam spheres while keeping the elbows close to the trunk and flexed at about $90^{\circ}$. Subjects rotated the spheres at natural cadence (twice), then as fast as possible with each hand while the other hand was kept immobile (twice) and finally, at fast cadence with both hands (twice). Each trial lasted $5 \mathrm{~s}$ and was followed by a rest period of about $20 \mathrm{~s}$. Four characteristics were calculated from each recording: Range, Velocity, Maximum Slope and Coherence. Detailed definitions of these characteristics are shown in Table 1.

Statistics: The effect of ETOH exposure on neuromotor activity was evaluated with the Wilcoxon signed-rank test for paired data. The level of significance was set at 0.05 .

\section{Results}

ETOH in Blood and Alveolar air: Whereas ETOH was not detected in the blood of volunteers exposed to 250 and $500 \mathrm{ppm}$, the blood concentrations measured at 3 and $6 \mathrm{~h}$ during exposure to $1,000 \mathrm{ppm}$ were $0.229 \mathrm{mg} \%$ and $0.443 \mathrm{mg} \%$, respectively (Fig. 1a). ETOH in alveolar air was measured only in samples taken during the 1,000 ppm exposure. As can be seen in Fig. 1b, the concentration reached a steady-state $3 \mathrm{~h}$ after the start of exposure and ranged from $241 \pm 21.5 \mathrm{ppm}$ to $249 \pm 28.4$ ppm (mean $\pm \mathrm{SD})$.

Neuromotor Activity: The raw data obtained from the neuromotor tests are shown in Tables 2 and 3. The statistical test used showed significant results for velocity of alternating movements (diadochokinesia) with the right hand at maximal speed, for harmonic index with the right hand, for sway velocity with closed eyes and for tremor index with the right hand. The first three results were obtained at $500 \mathrm{ppm}(p=0.043)$, but no significant results could be observed at $1,000 \mathrm{ppm}$. Significant changes were observable for the Tremor Index at $0 \mathrm{ppm}$ but at no other ETOH concentration. Results of the Wilcoxon sign rank tests are shown in Table 4.

\section{Discussion}

This preliminary study was undertaken to see whether or not acute exposure to ETOH by inhalation at concentrations similar to or below $1,000 \mathrm{ppm}$ is likely to produce small neuromotor effects. Blood concentrations measured at 3 and $6 \mathrm{~h}$ during exposure to $1,000 \mathrm{ppm}$ were $0.229 \mathrm{mg} \%$ and $0.443 \mathrm{mg} \%$, respectively. This is far below the range of blood alcohol levels $(50-150 \mathrm{mg}$ $\%)$ that is usually associated with mild ethanol intoxication. The results also showed that the absorption from lungs was approximately $75 \%$ which is a higher value than the one usually reported $(\approx 62 \%)$ by Lester and Greenberg ${ }^{17)}$ in subjects exposed to concentrations ranging from 5,850 to $10,265 \mathrm{ppm}$ of ETOH and used by Pastino and colleagues ${ }^{1)}$ in their physiologically based pharmacokinetics (PBPK) model. Therefore, it appears that the fraction of ETOH absorbed in the lungs is higher at lower exposure concentrations.

ETOH diminishes the flow of nerve action potentials and can therefore be regarded as a central depressant, causing a delay of reflexes and reactions ${ }^{18}$. This mechanism can explain the significant decrease in 
Table 2. Comparison of pre and post-exposure results for reaction time, postural tremor and diadochokinesia in 5 healthy men to various concentrations of ethanol by inhalation for 6 hours (mean \pm SD)

\begin{tabular}{|c|c|c|c|c|c|c|c|c|}
\hline \multicolumn{9}{|c|}{ Reaction time (s) } \\
\hline & \multicolumn{2}{|c|}{$1,000 \mathrm{ppm}$} & \multicolumn{2}{|c|}{$500 \mathrm{ppm}$} & \multicolumn{2}{|c|}{$250 \mathrm{ppm}$} & \multicolumn{2}{|c|}{$0 \mathrm{ppm}$} \\
\hline & pre & post & pre & post & pre & post & pre & post \\
\hline Right & $0.197 \pm$ & $0.193 \pm$ & $0.193 \pm$ & $0.196 \pm$ & $0.191 \pm$ & $0.210 \pm$ & $0.213 \pm$ & $0.197 \pm$ \\
\hline hand & 0.039 & 0.022 & 0.028 & 0.024 & 0.023 & 0.029 & 0.018 & 0.021 \\
\hline Left & $0.191 \pm$ & $0.209 \pm$ & $0.197 \pm$ & $0.197 \pm$ & $0.198 \pm$ & $0.204 \pm$ & $0.210 \pm$ & $0.199 \pm$ \\
\hline hand & 0.029 & 0.039 & 0.041 & 0.054 & 0.031 & 0.054 & 0.033 & 0.027 \\
\hline \multicolumn{9}{|c|}{ Postural tremor } \\
\hline \multicolumn{9}{|c|}{ Tremor intensity $\left(\mathrm{m} / \mathrm{s}^{2}\right)$} \\
\hline Right & $0.124 \pm$ & $0.120 \pm$ & $0.125 \pm$ & $0.119 \pm$ & $0.117 \pm$ & $0.113 \pm$ & $0.107 \pm$ & $0.109 \pm$ \\
\hline hand & 0.024 & 0.013 & 0.013 & 0.017 & 0.016 & 0.012 & 0.015 & 0.009 \\
\hline Left & $0.113 \pm$ & $0.104 \pm$ & $0.117 \pm$ & $0.112 \pm$ & $0.118 \pm$ & $0.102 \pm$ & $0.097 \pm$ & $0.106 \pm$ \\
\hline hand & 0.023 & 0.024 & 0.026 & 0.041 & 0.011 & 0.012 & 0.008 & 0.018 \\
\hline \multicolumn{9}{|c|}{ Center frequency $(\mathrm{Hz})$} \\
\hline Right & $6.20 \pm$ & $6.30 \pm$ & $6.87 \pm$ & $6.65 \pm$ & $6.59 \pm$ & $6.43 \pm$ & $6.65 \pm$ & $6.67 \pm$ \\
\hline hand & 1.00 & 0.61 & 1.03 & 0.38 & 0.30 & 0.47 & 0.28 & 0.71 \\
\hline Left & $6.70 \pm$ & $7.06 \pm$ & $6.51 \pm$ & $6.75 \pm$ & $7.37 \pm$ & $6.56 \pm$ & $6.60 \pm$ & $6.78 \pm$ \\
\hline hand & 1.70 & 1.31 & 1.39 & 1.26 & 1.26 & 1.48 & 1.15 & 1.46 \\
\hline \multicolumn{9}{|c|}{ Frequency dispersion $(\mathrm{Hz})$} \\
\hline Right & $3.063 \pm$ & $3.138 \pm$ & $3.270 \pm$ & $3.180 \pm$ & $3.370 \pm$ & $3.400 \pm$ & $3.210 \pm$ & $3.310 \pm$ \\
\hline hand & 1.031 & 0.480 & 0.783 & 0.396 & 0.593 & 0.257 & 0.585 & 0.555 \\
\hline Left & $3.438 \pm$ & $3.775 \pm$ & $3.320 \pm$ & $3.440 \pm$ & $3.680 \pm$ & $3.550 \pm$ & $3.630 \pm$ & $3.440 \pm$ \\
\hline hand & 0.915 & 0.595 & 0.627 & 0.499 & 0.317 & 0.464 & 0.546 & 0.499 \\
\hline \multicolumn{9}{|c|}{ Tremor Index } \\
\hline Right & $1.084 \pm$ & $0.870 \pm$ & $1.009 \pm$ & $0.892 \pm$ & $0.871 \pm$ & $0.786 \pm$ & $0.860 \pm$ & $0.719 \pm$ \\
\hline hand & 0.185 & 0.104 & 0.289 & 0.204 & 0.172 & 0.188 & 0.057 & 0.201 \\
\hline Left & $1.060 \pm$ & $0.868 \pm$ & $0.995 \pm$ & $0.948 \pm$ & $0.891 \pm$ & $1.044 \pm$ & $1.050 \pm$ & $1.119 \pm$ \\
\hline hand & 0.479 & 0.228 & 0.488 & 0.285 & 0.318 & 0.273 & 0.183 & 0.211 \\
\hline
\end{tabular}

Max speed with both hands

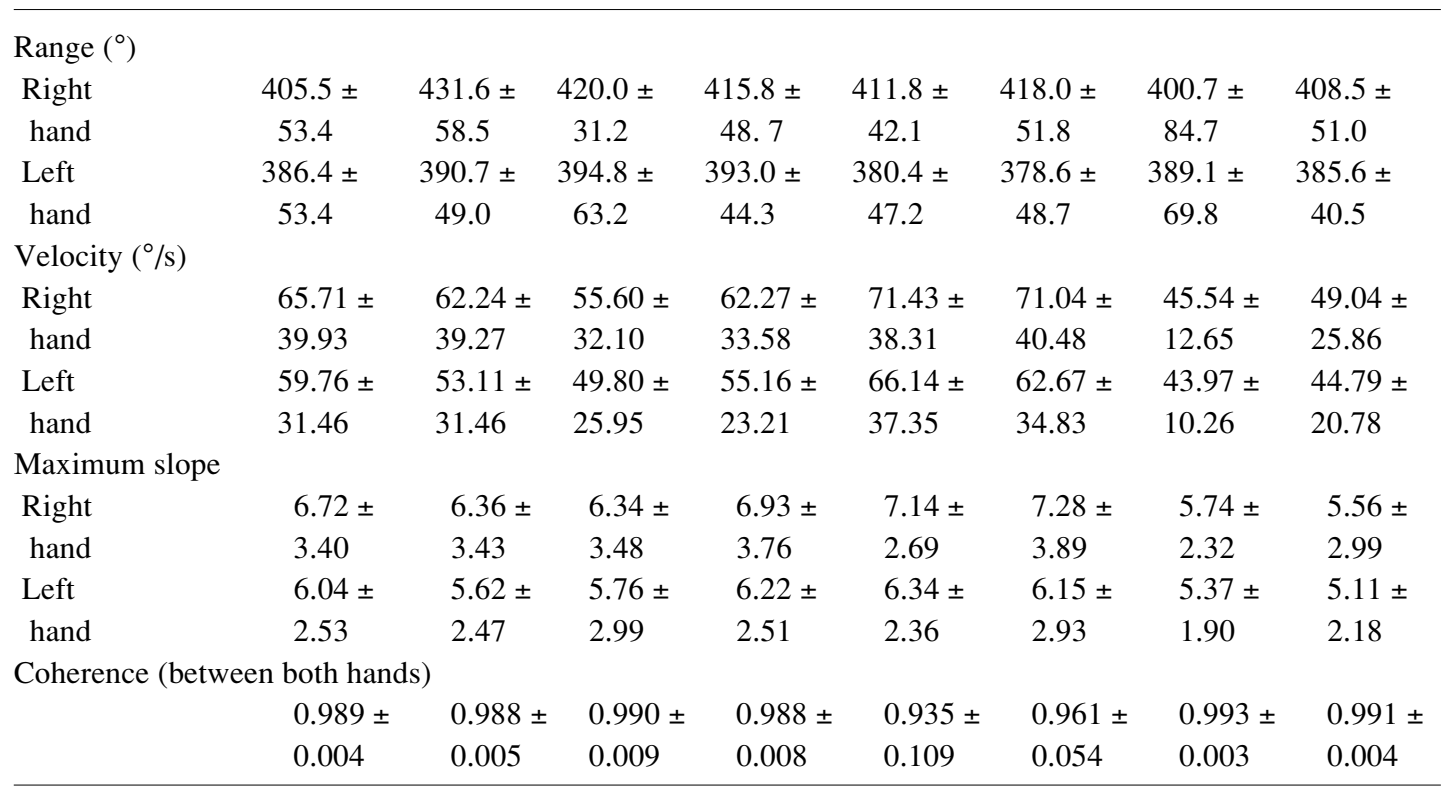


Table 3. Comparison of pre and post-exposure results for body sway in 5 healthy men to various concentrations of ethanol by inhalation for $6 \mathrm{~h}($ mean $\pm \mathrm{SD})$

\begin{tabular}{|c|c|c|c|c|c|c|c|c|}
\hline \multicolumn{9}{|c|}{ Body Sway } \\
\hline \multicolumn{9}{|c|}{ Transversal Sway (mm) } \\
\hline & \multicolumn{2}{|c|}{$1,000 \mathrm{ppm}$} & \multicolumn{2}{|c|}{$500 \mathrm{ppm}$} & \multicolumn{2}{|c|}{$250 \mathrm{ppm}$} & \multicolumn{2}{|c|}{$0 \mathrm{ppm}$} \\
\hline & pre & post & pre & post & pre & post & pre & post \\
\hline Eyes open & $4.33 \pm 1.04$ & $3.50 \pm 1.11$ & $4.88 \pm 2.31$ & $4.45 \pm 1.10$ & $4.04 \pm 1.43$ & $4.22 \pm 2.12$ & $3.87 \pm 1.19$ & $3.00 \pm 0.52$ \\
\hline Eyes closed & $5.30 \pm 0.92$ & $3.22 \pm 1.00$ & $3.64 \pm 1.36$ & $4.20 \pm 2.58$ & $3.86 \pm 2.37$ & $3.64 \pm 0.76$ & $2.83 \pm 0.78$ & $3.30 \pm 1.43$ \\
\hline \multicolumn{9}{|c|}{ Sagittal Sway (mm) } \\
\hline Eyes open & $4.63 \pm 2.34$ & $7.10 \pm 5.19$ & $5.36 \pm 3.63$ & $4.35 \pm 0.82$ & $5.20 \pm 2.19$ & $4.88 \pm 3.19$ & $3.78 \pm 0.71$ & $3.62 \pm 0.46$ \\
\hline Eyes closed & $6.13 \pm 2.84$ & $4.90 \pm 2.86$ & $4.22 \pm 1.74$ & $3.80 \pm 1.63$ & $5.36 \pm 1.19$ & $4.62 \pm 1.92$ & $4.80 \pm 1.51$ & $3.96 \pm 1.33$ \\
\hline \multicolumn{9}{|c|}{ Sway Area $\left(\mathrm{mm}^{2}\right)$} \\
\hline Eyes open & $467 \pm 160$ & $491 \pm 187$ & $677 \pm 537$ & $456 \pm 136$ & $488 \pm 295$ & $574 \pm 484$ & $427 \pm 198$ & $316 \pm 102$ \\
\hline Eyes closed & $335 \pm 88$ & $267 \pm 153$ & $255 \pm 110$ & $282 \pm 142$ & $348 \pm 223$ & $289 \pm 127$ & $252 \pm 74$ & $257 \pm 124$ \\
\hline \multicolumn{9}{|c|}{ Sway Velocity $(\mathrm{mm} / \mathrm{s})$} \\
\hline Eyes open & $13.67 \pm 1.53$ & $12.33 \pm 1.53$ & $15.40 \pm 2.97$ & $12.75 \pm 2.50$ & $13.20 \pm 2.17$ & $12.60 \pm 3.05$ & $14.75 \pm 3.78$ & $14.75 \pm 2.63$ \\
\hline Eyes closed & $9.0 \pm 1.0$ & $7.8 \pm 1.5$ & $8.8 \pm 0.8$ & $9.2 \pm 1.9$ & $8.6 \pm 1.8$ & $8.4 \pm 0.9$ & $10.0 \pm 2.2$ & $9.0 \pm 1.6$ \\
\hline
\end{tabular}

Table 4. Results ( $p$ values) of the Wilcoxon sign rank test for reaction time, postural tremor, alternating movements (diadochokinesia) and body sway after various inhalation exposures to ethanol $(6 \mathrm{~h})$ in 5 healthy men

\begin{tabular}{|c|c|c|c|c|c|c|c|c|}
\hline \multirow{3}{*}{$\begin{array}{l}\text { Measured parameters } \\
\text { Hands }\end{array}$} & \multicolumn{8}{|c|}{ Ethanol exposure concentrations (ppm) } \\
\hline & \multicolumn{2}{|c|}{1,000} & \multicolumn{2}{|c|}{500} & \multicolumn{2}{|c|}{250} & \multicolumn{2}{|c|}{0} \\
\hline & Left & Right & Left & Right & Left & Right & Left & Right \\
\hline Reaction time & 0.068 & 0.715 & 0.786 & 0.893 & 0.500 & 0.042 & 1.000 & 0.144 \\
\hline \multicolumn{9}{|l|}{ Postural tremor } \\
\hline Tremor intensity & 0.144 & 0.713 & 0.686 & 0.892 & 0.068 & 0.354 & 0.225 & 0.892 \\
\hline Centre frequency & 0.273 & 0.715 & 0.345 & 0.345 & 0.225 & 0.416 & 0.686 & 0.893 \\
\hline Frequency dispersion & 0.068 & 1.000 & 0.500 & 0.498 & 0.465 & 0.492 & 0.500 & 0.715 \\
\hline Harmonic index & 0.715 & 1.000 & 0.043 & 0.893 & 0.686 & 0.345 & 0.686 & 0.686 \\
\hline Tremor index & 0.273 & 0.068 & 0.893 & 0.225 & 0.500 & 0.354 & 0.500 & 0.043 \\
\hline \multicolumn{9}{|c|}{ Diadochokinesia (fast speed) } \\
\hline Range & 1.000 & 0.068 & 0.893 & 0.500 & 0.893 & 0.686 & 0.893 & 0.500 \\
\hline Velocity & 0.068 & 0.144 & 0.345 & 0.043 & 0.500 & 0.893 & 0.893 & 0.686 \\
\hline Max. Slope & 0.068 & 0.068 & 0.225 & 0.080 & 0.500 & 0.500 & 0.686 & 0.893 \\
\hline Coherence & \multicolumn{2}{|c|}{1.000} & \multicolumn{2}{|c|}{0.500} & \multicolumn{2}{|c|}{0.225} & \multicolumn{2}{|c|}{0.225} \\
\hline \multicolumn{9}{|l|}{ Body sway } \\
\hline Eyes & open & closed & open & closed & open & closed & open & closed \\
\hline Transversal sway & 0.715 & 0.109 & 0.686 & 0.225 & 0.715 & 0.786 & 0.345 & 0.500 \\
\hline Sagittal sway & 1.000 & 0.109 & 0.500 & 0.345 & 0.588 & 0.581 & 0.893 & 0.684 \\
\hline Sway area & 0.465 & 0.285 & 0.893 & 0.138 & 0.500 & 0.786 & 0.500 & 0.343 \\
\hline Sway velocity & 0.854 & 0.180 & 0.581 & 0.043 & 0.705 & 0.257 & 0.713 & 1.000 \\
\hline
\end{tabular}

diadochokinesia velocity (maximal speed) and Harmonic Index (right hand) and for the increasing sway velocity (closed eyes) observed after the 500 ppm exposure. Nevertheless, since these neuromotor changes were not observed after the 1,000 ppm exposure, these results should be interpreted cautiously. Concerning the postural tremor, Jones ${ }^{3)}$ reported that blood concentrations had to be higher than $50-70 \mathrm{mg} \%$ to produce significant changes 
in the postural tremor in men who ingested $0.68 \mathrm{~g} / \mathrm{kg}$ of ETOH. Nevertheless, the test battery used by Jones was quite different (i.e. less sensitive) from the one used in the present study, and the blood concentrations measured were still about 113-160 times lower than those needed to produce such an effect. The decrease in the Tremor Index (right hand) observed at $0 \mathrm{ppm}$ was not considered as significant since 1) this neuromotor alteration was not observed at higher exposure concentrations and 2) the 0 ppm exposure was the first of all exposures and we concluded that it is possible that subjects were not completely familiar with this procedure at the time. It should also be noted that the Tremor Index is an overall summary index which incorporates Tremor Intensity (RMS), Median Frequency, Standard Deviation of median frequency and Harmonic Index transformed in z-scores,so that any value deviating significantly from the norm established by the manufacturer will contribute a smaller than usual amount to the Tremor index ${ }^{12,19)}$. (For the equations used, see Edwards and Beuter, 1999 ${ }^{19)}$ ). We can further conclude that since all parameters deviated slightly from the norm at $0 \mathrm{ppm}$, the overall sum of all parameters was lower than what was expected, resulting in a significant change in the Tremor Index. The Harmonic Index compares the tremor frequency pattern with the pattern of a single harmonic oscillator which would have a harmonic index of 1 . This index decreases when the tremor is composed of many oscillations as is physiological tremor. It quantifies the regularity of the oscillations by means of concentrations of spectral power in narrow frequency ranges. It is the centre of mass of the sorted spectrum ${ }^{19}$. Therefore, it can be understood that oscillations were less regular at the end of the 500 ppm than before exposure, but since the decrease in the Harmonic Index was not observed at $1,000 \mathrm{ppm}$, it was not considered to be a significant neuromotor change. It has also been proposed that when ETOH is ingested, blood concentrations have to reach $60 \mathrm{mg} \% \mathrm{ml}$ for a significant increase in body sway to be observed ${ }^{14)}$. Blood levels measured in the present study are far below those values and this may explain why body sway was not altered by exposure to ETOH in this dose range.

Maximum movement speed tends to exacerbate problems more readily than normal speed because the neuromuscular system is approaching its functional limits $^{9,16)}$. It is believed that differences invisible at normal cadence become clear when the neuromuscular system approaches its functional limits and coordinating the two hands at fast cadence is likely to exacerbate problems more than using only one hand at a time. It was suggested that although the RAMs measure is a precise and reliable method, the analysis of the results may not be sophisticated enough to detect the subtle differences that characterize early signs of neurotoxicity ${ }^{9}$.

It is important to mention that the degree of the neuromotor changes will depend on the nature of the performance task and the individual's tolerance of the effects of ETOH on the $\mathrm{CNS}^{3,20)}$. One of the major problems in assessing motor functions is the high intraindividual variation, and in the present study $(n=5)$ this variation may have played a significant role. On the other hand, since exposure to 1,000 ppm of ETOH does not induce significant neuromotor changes, it is unlikely that exposure encountered on refuelling, at concentrations up to $43 \mathrm{ppm}$ may induce acute neuromotor effects in normal populations ${ }^{1)}$. Nevertheless, it is possible that tendencies encountered in some of the neuromotor tests become significant in more sensitive populations, in plant workers with physical activity during work which is known to enhance ventilation rate and therefore absorption, or as a result of repeated exposures.

In conclusion, this study showed that acute exposure to ethanol at $1,000 \mathrm{ppm}$ or lower or to concentrations that could be encountered on refuelling is not likely to cause any significant neuromotor changes in healthy males, but in the near future, it would be worthwhile to assess the chronic neuromotor effects of ethanol after inhalation exposure in the perspective of public health.

Aknowledgments: We thank G. Charest-Tardif and Christine Després for their excellent technical support. This research was supported by the Réseau de Recherche en Santé Environnementale du FRSQ, Québec.

\section{References}

1) GM Pastino, B Asgharian, K Roberts, MA Medinsky and JA Bond: A comparison of physiologically based pharmacokinetic model predictions and experimental data for inhaled ethanol in male and female B6C3F1 mice, F344 rats and humans. Toxicol Appl Pharmacol 145, 147-157 (1997)

2) ACGIH. Documentation of the Threshold Limit Values and Biological Exposure Indices. $6^{\text {th }}$ American Conference of Governmental Industrial Hygienists Cincinnati, OH, 1991.

3) AW Jones: Pharmacokinetics of ethanol in saliva : comparison with blood and breath alcohol profiles, subjectives feelings of intoxication and diminished performance. Clin Chem 39, 1837-1844 (1993)

4) AW Jones: Excretion of low-molecular weight volatile substance in human breath: focus on endogenous ethanol. J Anal Toxicol 9, 246-250 (1985)

5) HG Holford: Clinical pharmacokinetics of ethanol. Clin Pharmacokin 13, 273-292 (1987)

6) R Rigal: Motricité humaine. Fondements et applications pédagogiques. Tome I: Neurophysiologie sensorimotrice. Québec, Presses de l'Université du Québec, 1995: 80-107.

7) MD Escarajabal: Concurrent administration of diethyldithlocarbamate and 4-methylpyrazole enhances ethanol-induced locomotor activity: the role of brain ALDH. Psychopharmacol 160, 339-343 (2002) 
8) R Tardif, L Liu and M Raizenne: Exhaled acetaldehyde by human subjects exposed to low levels of ethanol: a pilot-study. Tox. Letters 135, S-138 (2002)

9) A Beuter, A de Geoffroy and R Edwards: Analysis of rapid alternating movements in Cree subjects exposed to methylmercury and in subjects with neurological deficits. Environ Res 80, 64-79 (1999)

10) A Beuter and R Edwards: Tremor in Cree subjects exposed to methylmercury :A preliminary study. Neurotoxicol Teratol 20, 581-589 (1998)

11) R Letz, F Gerr and D Harris-Abbot: Heterogeneity of effects of ethanol ingestion on postural stability as measured by two devices. Neurotoxicology 15, 603608 (1994)

12) C Després, D Lamoureux and A Beuter: Standardization of a neuromoteur test battery: the Catsys system. Neurotoxicology 21, 725-735 (2000)

13) R Letz, F Gerr, D Harris-Abbot, R Dick: A comparison of standing steadiness measurements from two devices: covariates and normal values. Neurotoxicol Teratol 18, 83-88 (1996)

14) T Kubo, Y Sakata, T Matsunaga, A Koshimune, S Sakai, K Ameno and I Ijiri: Analysis of body sway pattern after alcohol ingestion in human subjects. Acta Otolaryngol 468, 247-252 (1989)

15) K Savolainen and V Riihimäki: Xylene and alcohol involvement of the human equilibrium system. Acta Pharmacol Toxicol 49, 447-451 (1981)

16) A Beuter, D Mergler, A de Geoffroy, L Carrière, S Bélanger, L Varghese, J Sreekumar and S Gauthier: Diadochokinesimetry : A study of patients with Parkinson's disease and manganese exposed workers. Neurotoxicology 15, 655-664 (1994)

17) D Lester and LA Greenberg: The inhalation of ethyl alcohol by man. Q. J. Stud Alcohol 12, 167-178 (1951)

18) T Ledin and M Ödkvist: Effects of alcohol measured by dynamic posturography. Acta Otolaryngol 481, 576581 (1991)

19) R Edwards and A Beuter: Indexes for identification of abnormal tremor using computer tremor evaluation systems. IEEE Trans Biomed Eng. 46, 895-899 (1999)

20) RS Kennedy, JJ Turnage and WP Dunlap: The use of dose equivalency as a risk assessment index in behaviroal neurotoxicology. Neurotox Teratol 167-175 (1992) 